\title{
The Hearing Ability of the Red Sea Bream Pagrus major
}

\author{
Hiroko Ishioka, ${ }^{* 1}$ Yoshimi Hatakeyama, ${ }^{* 2}$ and Seiji Sakaguchii ${ }^{* 3}$ \\ (Received October 2, 1987)
}

\begin{abstract}
The auditory sensitivity of the red sea bream, Pagrus major C. TEMminck et SCHLEGel, was determined by heart-beat conditioning using a sound coupled with a delayed electric shock. Sufficient care was taken in order to obtain a stable acoustic condition. Sound was projected from an airspeaker in a sound-proofed chamber in which the experimental tank was placed on an air spring.

The audible range of the red sea bream extended from 50 to $1000 \mathrm{~Hz}$ with a peak sensitivity of $-14.2 \mathrm{~dB}(0 \mathrm{~dB}=1 \mu \mathrm{bar})$ at $200 \mathrm{~Hz}$. On the basis of its responses to unconditioned sounds, it was suspected that the red sea bream was able to distinguish sound quality.
\end{abstract}

Auditory-stimuli or vibrations generated, through many kinds of causes such as construction, explosions, motors and so on, affect fish life in various ways. In estimating the effects of auditosy-stimuli on fish, it is necessary to know the effective range between a detectable sound level and a lethal sound level. In the red sea bream, we obtained the lethal sound level in an energy flux density and the sound level producing behavioral disturbance by observing the occurrence of startle response in previous experiments. ${ }^{1)}$ However, the lowest detectable sound level, the startingpoint of the effective range of sound, is not yet known for this fish.

The sensitivity of fish to detect a sound is usually expressed in terms of a threshold, often defined as the sound level to which a fish responds in a specific manner. Audiograms, showing the auditory thresholds of sounds at different frequencies, have been obtained in more than twenty species of fishes up to now.

In the present study, we attempted to obtain the audiogram of the red sea bream by classical conditioning method of heart beat. We adopted this method because it seemed to be useful for every teleost fish and found that in the red sea bream also, the conditioning of the heart beat response was easily establishable in a short period.

\section{Materials and Methods}

Three-year-old fish were obtained from a fish farm in Hiroshima (Nomi Suisan Co.) and reared for about one month before the experiment. The fish were supplied with raw oyster twice a day except for the 2 days prior to the experiment. The size of the fish used in the experiment was $25.5 \pm 3.61$ (mean \pm s.d.) $\mathrm{cm}$ in fork length and $380.2 \pm 144.3$ (mean \pm s.d.) $g$ in body weight. The day before the experiment, each fish was operated on in order to install a leading-out bipolar electrode. This electrode was used both for applying electric shock to the fish and for recording of the cardio-signal of the fish on a cardiograph. The electrode was made from a fish hook which was re-shaped according to the shape of fish heart and body surface. This hook was then connected to the lead-code insulated with paint, and the connecting part was covered with silicon rubber tube. The pointed end was stripped off slightly for conduction of electricity and the another pointed edge was used for hooking the electrode into the muscle around the heart. After the operation the fish was kept in a plastic net-cage and allowed to recover, and then the cardiogram was examined to determine whether the operation had been successful. Successfully treated fish was kept in a cage at the exact position where the sound level had been determined previously. After $16 \mathrm{~h}$, the experiment was started.

The water temperature during the experiments was between $21.6^{\circ} \mathrm{C}$ and $26.9^{\circ} \mathrm{C}$. The temperature level was influenced by the atmospheric temperature, because a running sea water system

*1 Nansei Regional Fisheries Research Laboratory, Ohno, Saeki, Hiroshima 739-04, Japan (石用宏子：南西 海区水座研究所).

*2 National Research Institute of Fisheries Engineering, Kachidoki, Chuo, Tokyo 104, Japan (鼻山良巳： 水産工学研究所).

*3 National Research Institute of Aquaculture, Nansei, Mie 516-01, Japan (阪口清次: 羕殖研究所). 


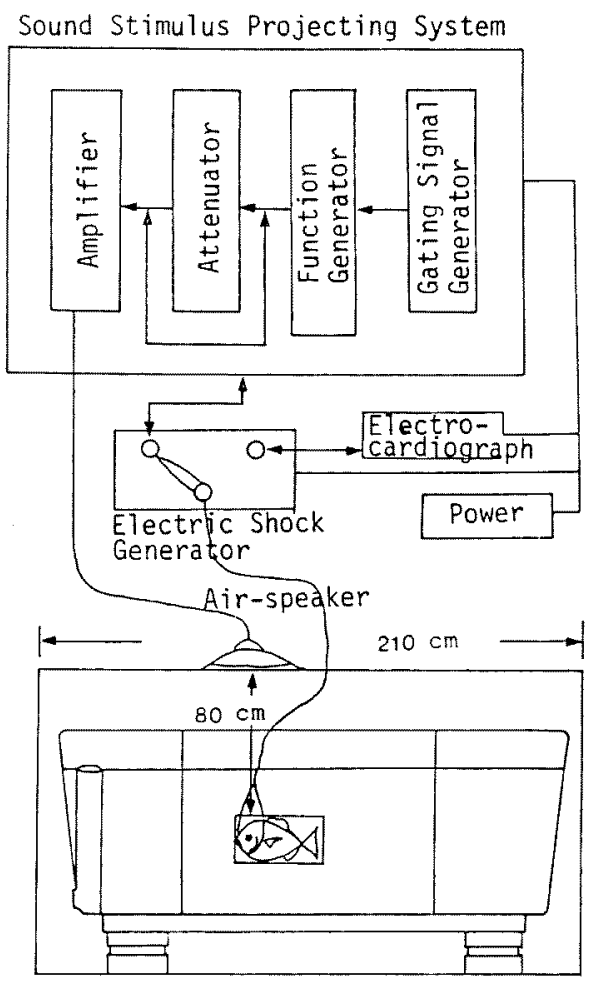

Fig. 1. Experimental equipment.

could not be used in order to minimize the level of environmental noise around the fish.

As this experiment was designed to obtain an audiogram of marine fish, we had to take the greatest possible care to keep the experimental environment free of noise such as the sounds of footsteps, voices and floor vibration produced by passing cars near the experimental station. A simple sound-proof chamber was therefore assembled. Walls made of 2 -cm-thick board surrounded the 1-ton experimental tank and the inner side of the wall was fitted with rubber sheeting 5 -mm thick. The ceiling material was also thick board and the inner side of the ceiling was covered with glass wool $5-\mathrm{cm}$ thick for sound absorption, while the outer side was fitted with the same type of rubber sheet. The sound for use in the experiment was released from an air-speaker fitted into the ceiling. The experimental tank was placed on a steel frame supported by an air-spring (Ishikawajima Noise Control Co.) set under each of the four corners. These fittings were able to decrease the noise level in the experimental tank considerably. The decrease in the background noise spectrum level was estimated to be about $10 \mathrm{~dB}$ or more over $50 \mathrm{~Hz}$.

The experimental equipment is illustrated in Fig. 1. The system for generation of the audiosignal has been previously described ${ }^{13}$ except for the air-speaker, which was able to generate underwater sound with a smaller particle displacement, larger amplitude and smaller distortion than an underwater speaker, even below $200 \mathrm{~Hz}$.

Before starting the experiment, the quality of the audiosignal was determined at the particular position occupied by the fish using a hydrophone, an oscilloscope and a sound pressure measuring system. The audio-signals used were pure tones produced electrically with a range of frequency between 50 and $1000 \mathrm{~Hz}$. The electrocardiograph (Fukuda Denshi Co., Type FD-14) was reconditioned to detect the voltage current of the fish cardio-signal and the height of $1 \mathrm{mV}$ was set as $20 \mathrm{~mm}$.

At a particular position in the sound fields, where the sound level was pre-determined, conditioning experiments were carried out. At each frequency examined, conditioning was performed with the sound coupled to a 0.5 -s delayed electric shock of $20 \mathrm{~V} \mathrm{DC}$ lasting for $0.1 \mathrm{~s}$. The sound pressure and duration of the sound were between 130 and $146 \mathrm{~dB}(0 \mathrm{~dB}=1 \mu \mathrm{Pa})$ and $200 \mathrm{~ms}$, respectively. Full conditioning was complete within 7 trials and could be achieved within one hour. In a recovery period of 3 hours from conditioning

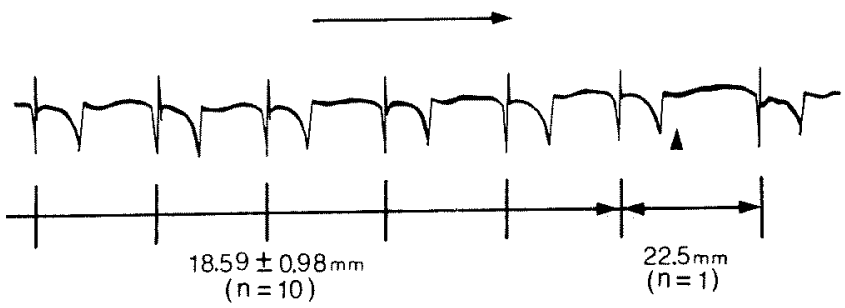

Fig. 2. Example of the electrocardiogram showing a heart beat suppression by a conditioned sound. Note the elongation of the interval distance after the projection of the trained sound.

$\Delta$ : sound projection. 
trials, the experiment for determining the threshold was started after the circuit for electric shock generation was disconnected. The stimulus level of the sound was progressively increased from a sound-proof condition in fixed increments of 2.5 $\mathrm{dB}$ and the cardiogram was observed. A positive response was defined by a statistically significant inhibition of heart beat interval compared with that recorded between trials. An example of a positive response is shown in Fig. 2. The trials were carried out several times at the same level of the examined sound. The threshold was defined as the median sound pressure between that causing a continuous positive response and that causing a continuous negative response. When the posi-
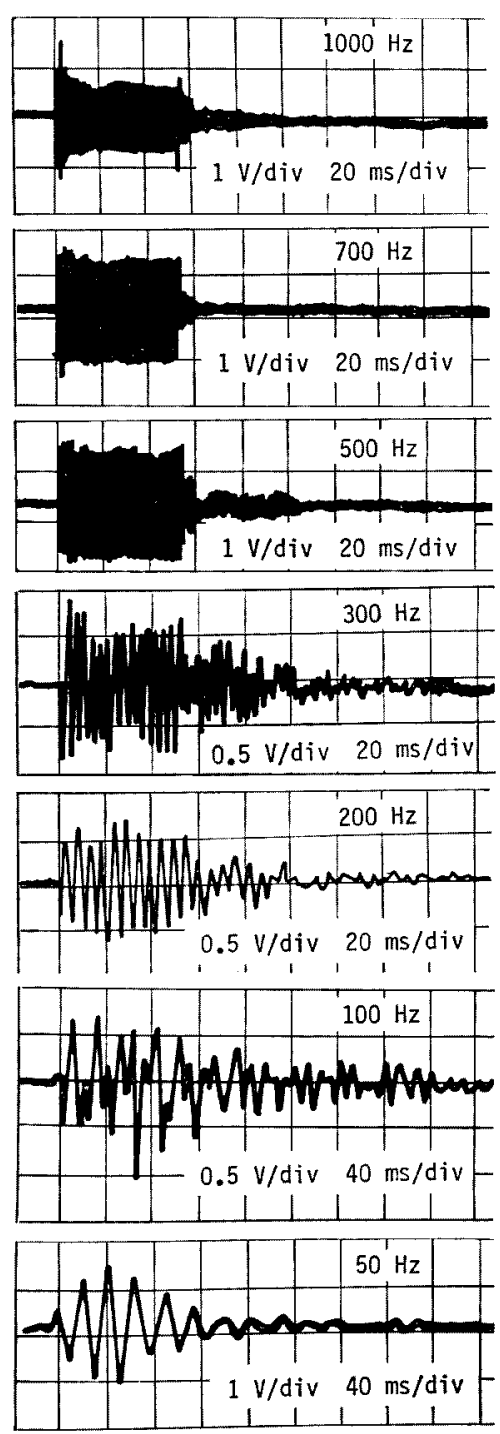

Fig. 3. Sound wave forms projected at the position where the fish was kept. tive and negative responses were obtained at the same level of acoustic pressure, the exact level was defined as the threshold level.

\section{Results}

As the experimental environment was a narrow space surrounded by parallel walls, the reflection of the sound was first examined at the exact position where the fish would be set. Details of the instrument for measuring underwater sound have been given previously. ${ }^{11}$

The wave forms shown in Fig. 3 correspond to those obtained with burst waves of $50,100,200$, $300,500,700$ and $1000 \mathrm{~Hz}$ in frequency which were projected from the air-speaker for $50 \mathrm{~ms}$. Reverberations which occurred after sound projection were not very large at 50, 200, 500, 700 and $1000 \mathrm{~Hz}$, but they were somewhat larger at 300 and $100 \mathrm{~Hz}$. In the audiogram experiment, however, the sound was projected for $200 \mathrm{~ms}$ in order to stress the effect of the exact sound quality.

The thresholds obtained are listed in Table 1 and the mean thresholds against background noise are plotted in Fig. 4. The sensitive frequencies

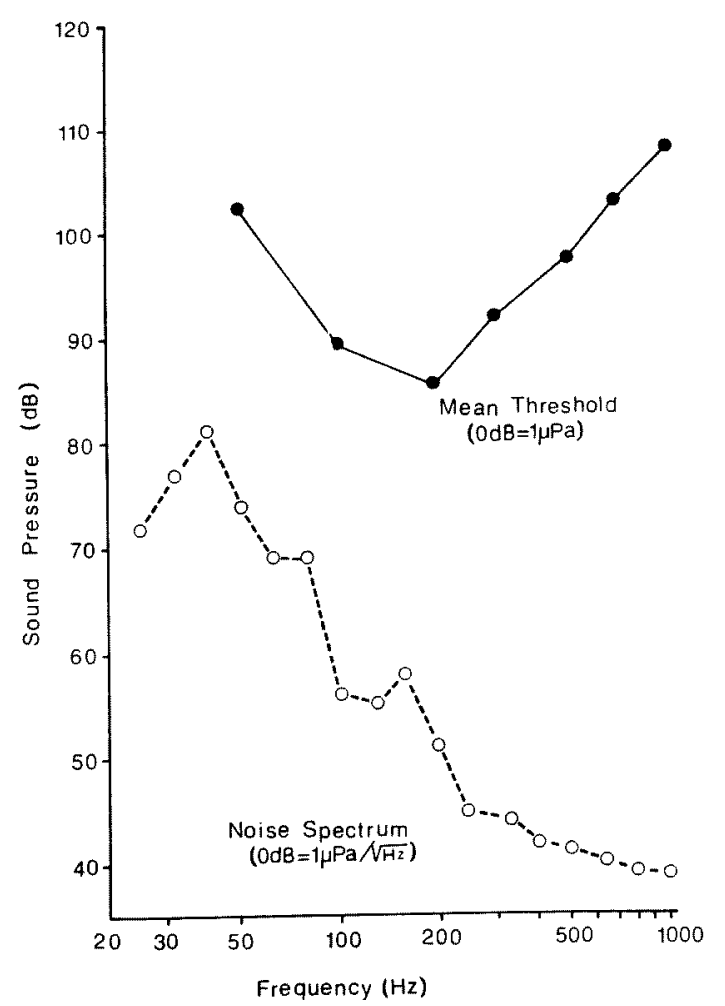

Fig. 4. Audiogram of red sea bream and the spectrum of background noise. 
Table 1. Auditory thresholds for red sea bream obtained by classical conditioning of heartbeat. Values are mean \pm (s.d.) of 5 fish in $\mathrm{dB}\left(0 \mathrm{~dB}=1 \mu \mathrm{Pa}, 1 \mu \mathrm{Pa}=1 \mu \mathrm{bar} \times 10^{-5}\right)$. Boxed data represent used for the audiogram in Fig. 4

\begin{tabular}{cccccccc}
\hline \hline $\begin{array}{c}\text { Conditioning } \\
\text { Frequency }\end{array}$ & 50 & 100 & 200 & $\begin{array}{c}\text { Frequency } \\
300\end{array}$ & 500 & 700 & 1000 \\
\hline 50 & $\overline{102.7}$ & 104.8 & 87.8 & 91.7 & 100.7 & 111.5 & 112.3 \\
& $(3.02)$ & $(13.46)$ & $(4.80)$ & $(3.27)$ & $(3.09)$ & $(7.33)$ & $(12.44)$ \\
100 & 107.8 & 89.7 & 93.0 & 89.8 & 98.1 & 105.1 & 106.8 \\
& $(19.75)$ & $(10.29)$ & $(11.45)$ & $(10.91)$ & $(9.30)$ & $(12.02)$ & $(6.60)$ \\
200 & 110.5 & 103.8 & $\overline{85.8}$ & 90.3 & 102.4 & 111.9 & 113.7 \\
& $(24.67)$ & $(26.29)$ & $(1 \overline{11.05})$ & $(17.56)$ & $(11.59)$ & $(12.14)$ & $(10.80)$ \\
300 & 104.3 & 102.7 & 101.2 & 91.9 & 104.2 & 110.3 & 112.7 \\
& $(8.24)$ & $(22.38)$ & $(21.60)$ & $(5.80)$ & $(6.51)$ & $(6.08)$ & $(4.57)$ \\
500 & 102.1 & 98.3 & 91.5 & 98.5 & 97.7 & 109.0 & 117.7 \\
& $(15.44)$ & $(11.53)$ & $(12.88)$ & $(19.02)$ & $(7.58)$ & $(10.89)$ & $(10.57)$ \\
700 & 114.3 & 103.1 & 109.4 & 98.9 & 115.2 & $\overline{103.1}$ & 115.4 \\
& $(19.55)$ & $(18.57)$ & $(6.05)$ & $(20.20)$ & $(12.79)$ & $(9.28)$ & $(5.89)$ \\
1000 & 120.8 & 107.2 & 103.8 & 104.2 & 109.8 & 104.5 & $\overline{108.0}$ \\
& $(15.47)$ & $(16.12)$ & $(16.69)$ & $(14.10)$ & $(18.85)$ & $(6.07)$ & $(11.46)$ \\
\hline
\end{tabular}

ranged from $50 \mathrm{~Hz}$ to $1000 \mathrm{~Hz}$ and the lowest threshold to pure tone was obtained at a frequency of $200 \mathrm{~Hz}$.

Variability was apparent in the data obtained at all frequencies, as shown in Table 1. While this could partly be attributed to individual differences among fish, it was also partly due to the experimental temperature. When the data obtained were analyzed in relation to the experimental temperature, fish responded more sensitively above $24.0^{\circ} \mathrm{C}$ in a frequency range between from 50 and $500 \mathrm{~Hz}$, although this tendency was not recognized at a frequency of over $700 \mathrm{~Hz}$.

Responses to unconditioned audiosignals are also presented in Table 1. At each frequency tested, the response of the fish to the trained pure tone was more definite than those to the other non-trained tones, while the patterns of hearing ability were more or less similar to the audiogram in Fig. 4, irrespective of conditioning frequency.

\section{Discussion}

When a fish responds to an audiostimulus as a life-or-death response or as a behavioral response, it is possible to identify such responses easily. Without a behavioral response, it is very difficult to judge whether a fish has perceived an audiosignal or not.

Various kinds of experiments have been attempted to determine fish audiograms. The basic principles involve conditioning by audiosignals in combination with physiological or be- havioral responses, such as avoidance behavior, changes in heart rate and feeding behavior, and so on. In the present experiment, classical conditioning of the heart rate in combination with electric shock was adopted to obtain a clear response at a particular position in the acoustic field.

Audiograms have previously been constructed using various conditioning methods.

Tavolga and Wodinsky ${ }^{2}$ recorded the audiograms of 9 species of marine fish using avoidance responses conditioned by electric shock and audiosignals. There was great variability in such audiograms in the frequency range and in the level of sound pressure. The most sensitive fish, Holocentrus ascensionis, responded to a sound of frequency between $100 \mathrm{~Hz}$ and $2400 \mathrm{~Hz}$ and the most sensitive frequency was $800 \mathrm{~Hz}$ with a threshold level of $-24.6 \mathrm{~dB} \quad(0 \mathrm{~dB}=1 \mu \mathrm{bar})$. In Equetes acuminatus, the lowest audible sound was $-39.8 \mathrm{~dB}$ at $600 \mathrm{~Hz}$. Four other species of fish, including Lutjanus apodus, had their most sensitive frequency between 100 and $400 \mathrm{~Hz}$ and the audible level was between -17.3 and $5.5 \mathrm{~dB}$. Chapman and Sand ${ }^{32}$ recorded the audiogram of two species of flatfish, Pleuronectes platessa and Limanda limanda, with a rather narrow band width between 20 and $200 \mathrm{~Hz}$, using heart rateelectric shock conditioning. Weiss, Strother and Hartig ${ }^{4)}$ determined the audiogram of Ictalurus nebulosus by shock-avoidance training in an aquatic shuttle box. The range of hearing extended from 100 to $4000 \mathrm{~Hz}$ with a peak sensitivity 
at 400 and $700 \mathrm{~Hz}$ and a level of $-28 \mathrm{~dB}(0 \mathrm{~dB}=1$ $\mu$ bar).

Hawkins ${ }^{3)}$ classified the auditory sensitivity of fish into three categories. One of these was the audiogram for particle motion sensitive fish in which the thresholds rose steeply above 100-160 $\mathrm{Hz}$ and did not fall below $-10 \mathrm{~dB}(0 \mathrm{~dB}=1 \mu \mathrm{bar})$, even at their most sensitive frequencies. These species included Limanda limanda, Pleuronectes platessa, Salmo salar, Gobius niger, Perca fluviatilis, Acerina cernus, Lucioperca sandra, Opsanus tau and Tautoga onitis. Second category included fish with a much wider frequency range and a much greater sensitivity to sound pressure. These include Ictalurus nebulosus, Semotilus atromaculatus, Cyprinus carpio, several species of the genus Astyanax, Eucaspius delineatus, and Carassius auratus. Many species like the cod, Gadus morhua, the sea bream, Sargus annularis and Adioux xantherythius were included in the third category. Taxonomically, no relationship between these fish as a group was found.

The red sea bream examined in this experiment was a member of the last group, for which the auditory range of frequency was below about 1 $\mathrm{kHz}$ and peak sensitivity was not very low.

Table 1 shows that the red sea bream responded more sensitively to the trained pure tone than to other non-trained tones. This may mean that the red sea bream is able to discriminate frequency, although its ability to distinguish sound quality remains unknown. In future, the ability of sound discrimination will be studied in carefully designed experiments.
The objective of the present experiment was to determine the sound level detectable by the red sea bream in the experimental tank. Under natural conditions, the threshold of the sound stimuli may change, since fish live in circumstances where they are exposed not to pure tone but to complex tones and there are several factors affecting the detectable level, such as background noise, uncomfortable temperatures, and so on.

Considering the ecological and physiological behavior of the red sea bream within the effective range for audiostimulation, it is concluded that the detectable level, avoidance level, level for appetite loss and the lethal level correspond roughly to $90-110,150-170 \mathrm{~dB}, 160-180 \mathrm{~dB}$, and 220-230 dB $(0 \mathrm{~dB}=1 \mu \mathrm{Pa})$, respectively. ${ }^{1,8)}$

\section{References}

1) Ishioka, H., Y. Hatakeyama, S. Sakaguchi, and S. Yajima: Bull. Nansei Reg. Fish. Res. Lab., 20, 59-71 (1986).

2) Tavolga, W. N. and J. Wodinsky: Bull. Amer. Mus. Nat. Hist., 126, Article 2, 177-246 (1963).

3) Chapman, C. J. and O. Sand: Comp. Biochem. Physiol., 47A, 371-385 (1974).

4) Weiss, B. A., W. F. Strother, and G. M. Hartig: Proc. Nat. Acad. Sci. USA, 64, 552-556 (1969).

5) Hawkins, A. D.: in "Hearing and Sound Communication in Fishes" (ed. by W. N. Tavolga, A. N. Popper, and R. R. Fay), Springer-Verlag, New York, Heidelberg, Berlin, 1981, pp. 109-133.

6) Umezawa, S., S. Sakaguchi, O. Fukuhara, M. Fujiya, and T. Ogawa: Bull. Nansei Reg. Fish. Res. Lab., 11, 47-55 (1978). 